\title{
Enhancement of SOX-2 expression and ROS accumulation by culture of A172 glioblastoma cells under non-adherent culture conditions
}

\author{
CHANG-NIM IM ${ }^{1-3}$, HYE HYEON YUN ${ }^{1,2}$, HYUNG JAE YOO ${ }^{1}$, \\ MYUNG-JIN PARK ${ }^{4}$ and JEONG-HWA LEE ${ }^{1-3}$ \\ ${ }^{1}$ Department of Biochemistry, ${ }^{2}$ Cancer Research Institute and ${ }^{3}$ Cancer Evolution Research Center, College of \\ Medicine, The Catholic University of Korea, Seoul 137-701; ${ }^{4}$ Division of Radiation Cancer Research, \\ Korea Institute of Radiological and Medical Sciences, Seoul 139-706, Republic of Korea
}

Received February 16, 2015; Accepted May 4, 2015

DOI: 10.3892/or.2015.4021

\begin{abstract}
More efficient isolation and identification of cancer stem cells (CSCs) would help in determining their fundamental roles in tumor biology. The classical tool for this purpose is anchorage-independent tumorsphere culture. We compared the effects of differently textured culture plates and serum deprivation on the acquisition of CSC properties of A172 glioblastoma cells. Cells were cultured on standard polystyrene-treated plates, ultra-low attachment, poly (2-hydroxyethyl methacrylate)-coated plates, and $1 \%$ agar-coated plates with $10 \%$ serum or in serum-free glioblastoma sphere medium (GBM). Based on mitochondrial reductase activity and subG1 proportions, non-adherent conditions had a greater impact on A172 cell viability than serum deprivation. Among the stemness-related genes, SOX-2 expression was significantly upregulated by serum deprivation under non-adherent conditions, while several epithelial-to-mesenchymal transition (EMT)-related genes were less dependent on serum. In addition, reactive oxygen species (ROS) accumulation in A172 cells was significantly increased in GBM under non-adherent conditions. Despite the correlation between SOX-2 induction and ROS accumulation, treatment with the ROS scavenger N-acetyl-1-cysteine did not prevent SOX-2 expression, suggesting that ROS accumulation is not an essential requirement for induction of SOX-2. Our results suggested that cultivation of cancer cells under conditions of serum deprivation in an anchorage-independent manner may enrich SOX-2-expressing CSC-like cells in vitro.
\end{abstract}

Correspondence to: Professor Jeong-Hwa Lee, Department of Biochemistry, College of Medicine, The Catholic University of Korea, 222 Banpo-daero, Seocho-gu, Seoul 137-701, Republic of Korea E-mail: leejh@catholic.ac.kr

Key words: glioblastoma, serum deprivation, cancer stem cells, anchorage independence, SOX-2

\section{Introduction}

A specific subpopulation of cancer cells, called cancer stem cells (CSCs), was recently proposed to be responsible for tumorigenesis and heterogeneity in primary cancers. This behavior was attributed to the extensive self-renewal activities and multipotent differentiation abilities of the CSCs (1). Furthermore, CSCs have enhanced ability to invade surrounding tissues by undergoing epithelial-to-mesenchymal transition (EMT), which results in local and distant metastasis (2). CSCs are also regarded as the cause of failure of chemotherapy and radiotherapy, leading to the recurrence of tumors $(3,4)$. Therefore, the isolation and identification of CSCs in vitro are important and basic processes for the development of novel strategies to treat cancer in vivo by targeting CSCs.

Specifically, CSCs express a series of proteins including the sex-determining region Y-box 2 (SOX-2), octamer-binding transcription factor 4 (OCT-4), CD133 (also known as prominin-1, PROM1) and nestin (5-10). CSCs also display enhanced ability for EMT and some transcription factors, such as TWIST, regulate EMT progress involved in metastasis $(11,12)$. CD44 and CD133 surface marker expression have been widely used to isolate CSCs in vitro using specific antibodies and fluorescence-activated cell sorting (FACS) $(4,13)$. However, the specificity and efficiency of CD133 in the enrichment of CSCs concerning stemness and self-renewal are complex and controversial (10). For example, neither the expression of stemness genes nor the self-renewal capacities of CD133 ${ }^{+}$ and CD133- cells were significantly different between freshly isolated glioma and glioma sphere cultures (14). It has been demonstrated that CSCs can proliferate under serum-free culture conditions in a non-adherent manner to form sphere-like structures (15-22). Thus, the culture of cancer cells under non-adherent conditions to allow sphere formation and/or evaluation of the expression of CSCs markers are the simplest and most convenient ways for enriching and identifying CSCs.

To induce anchorage-independent growth in vitro, various culture plate surface conditions have been applied with several 
supplemental factors, including epidermal growth factor (EGF) and basic fibroblast growth factor (bFGF) (23). The surface of standard cell/tissue culture plates is negatively charged and hydrophilic, and is widely used with diverse cell cultures, while poly (2-hydroxyethyl methacrylate) (poly-HEMA)-coated, agar-coated, or ultra-low attachment plates have been used in in vitro studies to investigate anchorage-independent growth of cells including CSCs (15-22). Agar plates are also used for anoikis, a form of programmed cell death that is induced by detachment of anchorage-dependent cells from the surrounding extracellular matrix (ECM) (24-27). The ultra-low attachment surface has a neutral, hydrophilic hydrogel coating that reduces binding of attachment proteins. This surface is useful to maintain cells in a suspended, unattached state, thereby preventing stem cells from attachment-mediated differentiation and preventing anchorage-dependent cells from dividing (28). Cells are usually grown as monolayers on normal culture plates where CSCs can proliferate and form spheres during long-term culture ( 2-3 weeks) under the three conditions noted above.

The malignant clinical outcome of glioblastoma is based on the aggressive invasion ability of cancer cells into the adjacent normal brain parenchyma, which eventually affects normal brain function despite standard therapies, such as radiotherapy $(21,29)$. Therefore, defining these characteristics of CSCs of glioblastoma that survive or proliferate even under non-adherent conditions is critical in strategies for the treatment of glioblastoma. Silginer et al (30) noted that poly-HEMA-mediated detachment promoted cell death of glioblastoma cells in a manner similar to integrin inhibition. Although Hong et al (31) reported that the spherical characteristic of CSCs was observed for long-term cultured glioblastoma cells in medium with or without serum, the combined effects of different surface and media compositions with or without serum on the expression of genes involved in stemness and EMT are not well understood.

The present study explored how A172 glioblastoma cells behave under different culture conditions, i.e., serum deprivation and on plates with different surface types. We examined whether these culture conditions affected gene expression in relation to stemness- and EMT-related genes together with viability, cell cycle and ROS generation.

\section{Materials and methods}

Cell culture. The human glioblastoma cell line A172 was purchased from American Type Culture Collection (ATCC; Manassas, VA, USA) and maintained in Dulbecco's modified Eagle's medium (DMEM; HyClone, Logan, UT, USA) containing $10 \%$ heat-inactivated fetal bovine serum (FBS), $100 \mathrm{U} / \mathrm{ml}$ penicillin and $100 \mathrm{mg} / \mathrm{ml}$ streptomycin at $37^{\circ} \mathrm{C}$ in a $5 \% \mathrm{CO}_{2}$ atmosphere. A172 cells were maintained in the above medium $(\mathrm{Nm})$ and grown as monolayers on polystyrene-treated tissue culture plates (NP). The cells $\left(1 \times 10^{5}\right.$ cells) were cultured under the following conditions for $72 \mathrm{~h}$ : i) $\mathrm{Nm}$ or serum-free glioblastoma sphere medium (GBM) containing EGF (10 ng/ml) and bFGF (10 ng/ml) (both from R\&D Systems, Minneapolis, MN, USA) as previously described (10,23), and ii) NP, ultra-low attachment plates (UP; Corning, Tewksbury, MA, USA), $20 \mathrm{mg} / \mathrm{ml}$ poly-HEMA-coated plates (HP) and
$1 \%$ agar-coated plates (AP). The morphology of cells was examined using an inverted phase contrast microscope (x200, magnification). To observe the effects of ROS scavengers on the induction of SOX-2, cells were treated for $72 \mathrm{~h}$ with 10 mM N-acetyl-l-cysteine (NAC; Sigma-Aldrich, St. Louis, MO, USA).

Plate preparation. Non-coated 6-well plates were coated with $1 \mathrm{ml}$ of poly-HEMA (20 mg/ml; Sigma-Aldrich), dried overnight at room temperature, and washed twice with phosphate-buffered saline (PBS) before use. For the agar plates, $1 \%$ agar (Sigma-Aldrich) solution in PBS was added to 6-well plates and allowed to solidify for $1 \mathrm{~h}$. The ultra-low attachment plates were purchased from Corning (Corning, NY, USA) and the polystyrene tissue culture plates were from SPL Life Sciences (Pocheon, Gyeonggi-do, Korea).

Cell viability assay. Cell proliferation was assessed as a function of metabolic activity using an EZ-Cytox Cell Viability Assay kit (ItsBio, Seoul, Korea). The assay is based on reduction of tetrazolium chloride to the water-soluble formazan by succinate-tetrazolium reductase, which forms part of the mitochondrial respiratory chain. After treatment with $20 \mu \mathrm{l} /$ well, cells were incubated for $2 \mathrm{~h}$ at $37^{\circ} \mathrm{C}$ in a $5 \% \mathrm{CO}_{2}$ atmosphere. Absorbance was measured on a microplate reader (Bio-Rad 680; Bio-Rad, Hercules, CA, USA) at $450 \mathrm{~nm}$. After subtraction of the background, the viability was determined as the ratio relative to the control and reported as the mean \pm standard error $(\mathrm{SE})$.

Quantitative real-time polymerase chain reaction ( $q R T-P C R$ ). Total RNA was isolated using AccuZol (Bioneer, Daejeon, Korea) and first-strand cDNA was synthesized by reverse transcription with $1 \mu \mathrm{g}$ of total RNA using a ReverTra Ace qPCR kit (Toyobo, Osaka, Japan). Quantitative real-time PCR was performed to validate the expression level using $\mathrm{SYBR}^{\circledR}$ Premix Ex Taq ${ }^{\mathrm{TM}}$ (Takara Bio, Otsu, Shiga, Japan) with specific primers (Table I) on an Applied Biosystems 7300 machine (Applied Biosystems, Carlsbad, CA, USA). The relative values for specific mRNA were calculated after normalization to the $\mathrm{Ct}$ value of $\beta$-actin in the same sample using the $2^{-\Delta \Delta \mathrm{Ct}}$ method.

Cell cycle analysis. Spheres were trypsinized for $5 \mathrm{~min}$ at $37^{\circ} \mathrm{C}$ in a $5 \% \mathrm{CO}_{2}$ atmosphere, neutralized with complete medium containing FBS, and centrifuged at 3,000 x $\mathrm{g}$ for 5 min. Single cells were then fixed with $70 \%$ ethanol at $-20^{\circ} \mathrm{C}$ overnight and incubated with a solution containing $5 \mu \mathrm{g} / \mathrm{ml}$ RNase A and $10 \mu \mathrm{g} / \mathrm{ml}$ propidium iodide (PI) (both from Sigma-Aldrich) for $30 \mathrm{~min}$ at room temperature. After washing twice with cold PBS, the cells were analyzed using a FACSCalibur (Becton-Dickinson, Bedford, MA, USA). Mean fluorescence intensities were obtained using CellQuest software (Becton-Dickinson).

Reactive oxygen species (ROS) measurement. Intracellular ROS levels in cells were measured using 5-(and-6)-carboxy-2',7'-dichlorodihydrofluorescein diacetate $\left(\mathrm{H}_{2} \mathrm{DCF}-\mathrm{DA}\right.$; Invitrogen, Carlsbad, CA, USA). Briefly, the cells were washed in PBS, trypsinized, and then neutralized with 
Table I. Primers for quantitative real-time PCR.

\begin{tabular}{|c|c|c|}
\hline Gene & Sequence $\left(5^{\prime}-3^{\prime}\right)$ & Product (bp) \\
\hline SOX-2 & $\begin{array}{l}\text { Forward: 5'-TACCTCTТCCTCCCACTCCA-3' } \\
\text { Reverse: 5'-ACТCTCСТCТTTTGCACCCC-3' }\end{array}$ & 268 \\
\hline Nestin & $\begin{array}{l}\text { Forward: 5'-CGGTGGCTCCAAGACTTCC-3' } \\
\text { Reverse: 5'-GGCACAGGTGTCTCAAGGGTA-3' }\end{array}$ & 156 \\
\hline OCT-4 & $\begin{array}{l}\text { Forward: 5'-CAGCGACTATGCACAACGAGA-3' } \\
\text { Reverse: 5'-GCCCAGAGTGGTGACGGA-3' }\end{array}$ & 196 \\
\hline CD133 & $\begin{array}{l}\text { Forward: 5'-ACCCAACATCATCCCTGTTCTT-3' } \\
\text { Reverse: 5'-AGCTCTTCAAGGTGCTGTTCATG-3' }\end{array}$ & 100 \\
\hline SNAIL & $\begin{array}{l}\text { Forward: 5'-CCTCCCTGTCAGATGAGGAC-3' } \\
\text { Reverse: 5'-CCAGGCTGAGGTATTCCTTG-3' }\end{array}$ & 235 \\
\hline ZEB1 & $\begin{array}{l}\text { Forward: 5'-GCCAATAAGCAAACGATTCTG-3' } \\
\text { Reverse: 5'-TTTGGCTGGATCACTTTCAAG-3' }\end{array}$ & 100 \\
\hline ZEB2 & $\begin{array}{l}\text { Forward: 5'-TTCCTGGGCTACGACCATAC-3' } \\
\text { Reverse: 5'-TGTGCTCCATCAAGCAATTC-3' }\end{array}$ & 159 \\
\hline TWIST & $\begin{array}{l}\text { Forward: 5'-GGAGTCCGCAGTCTTACGAG-3' } \\
\text { Reverse: 5'-TCTGGAGGACCTGGTAGAGG-3' }\end{array}$ & 200 \\
\hline SLUG & $\begin{array}{l}\text { Forward: 5'-GGGGAGAAGCCTTTTTCTTG-3' } \\
\text { Reverse: 5'-TCCTCATGTTTGTGCAGGAG-3' }\end{array}$ & 157 \\
\hline $\mathrm{N}$-cadherin & $\begin{array}{l}\text { Forward: 5'-ACAGTGGCCACCTACAAAGG-3' } \\
\text { Reverse: 5'-CCGAGATGGGGTTGATAATG-3' }\end{array}$ & 200 \\
\hline Vimentin & $\begin{array}{l}\text { Forward: 5'-GAGAACTTTGCCGTTGAAGC-3' } \\
\text { Reverse: 5'-GCTTCCTGTAGGTGGCAATC-3' }\end{array}$ & 162 \\
\hline$\beta$-actin & $\begin{array}{l}\text { Forward: 5'-AGTACTCCGTGTGGATCGGC-3' } \\
\text { Reverse: 5'-GCTGATCCACATCTGCTGGA-3' }\end{array}$ & 67 \\
\hline
\end{tabular}

SOX2, SRY (sex determining region Y)-box 2; OCT4, octamer-binding transcription factor 4; SNAIL, SNAI1; ZEB1, zinc finger E-box-binding homeobox 1; ZEB2, zinc finger E-box-binding homeobox 2.

PBS-containing FBS. After two washes with PBS and further centrifugation, the cells were resuspended in PBS with $20 \mu \mathrm{M}$ DCF-DA and incubated for $20 \mathrm{~min}$ in the dark at $37^{\circ} \mathrm{C}$. After the cells were resuspended in PBS, the fluorescence was measured using a FACSCalibur (excitation at $488 \mathrm{~nm}$ and emission at 515-545 $\mathrm{nm}$ ). The mean fluorescence intensity for 10,000 cells/sample was determined using CellQuest software.

Western blot analysis. Cells were washed twice with PBS and lysed with RIPA buffer $(150 \mathrm{mM} \mathrm{NaCl}, 1 \% \mathrm{NP}-40$, $0.5 \%$ sodium deoxycholate, $0.1 \%$ sodium dodecyl sulfate, $50 \mathrm{mM}$ Tris- $\mathrm{HCl}$ and $\mathrm{pH}$ 8.0) with protease inhibitor (Roche Diagnostics, Penzberg, Germany) on ice for $30 \mathrm{~min}$. Protein concentration was determined using a BCA Protein Assay kit (Pierce Biotechnology, Rockford, IL, USA). Equal amounts of protein were separated by $10 \%$ sodium dodecyl sulfate polyacrylamide gel electrophoresis (SDS-PAGE) and transferred onto nitrocellulose membranes (Millipore, Billerica, MA, USA). The membranes were incubated for $1 \mathrm{~h}$ with $5 \%$ dried skim milk in TBST $(20 \mathrm{mM}$ Tris, $137 \mathrm{mM} \mathrm{NaCl}$ and $0.1 \%$ Tween 20 ) buffer and then incubated with primary antibodies to SOX-2 (Santa Cruz Biotechnology, Santa Cruz, CA, USA), SOD1 (Enzo Life Sciences, Farmingdale, NY, USA) and SOD2 (Abcam, Cambridge Science Park, Cambridge,
UK). Anti- $\beta$-actin antibody (Sigma-Aldrich) was used as an internal control. After incubation with horseradish peroxidase-conjugated secondary IgG (Santa Cruz Biotechnology), the immunoreactive bands were visualized on an enhanced chemiluminescence substrate (Thermo Fisher Scientific, Waltham, MA, USA). For quantification of the relative protein levels, densitometric analysis was carried out using Image $\mathbf{J}$ software (National Institutes of Health, Bethesda, MD, USA). The expression ratio relative to the control was calculated after normalization with the intensity of $\beta$-actin from each group.

Statistics. Student's t-test was used for comparison of differences between two groups. Each experiment was repeated at least three times. In all analyses, $\mathrm{P}<0.05$ was taken to indicate statistical significance.

\section{Results}

Cells have distinct morphologies and adherence patterns under various cell culture conditions. A172 cells were cultured for $72 \mathrm{~h}$ in various culture environments differing in plate and media conditions, as described in the Materials and methods. The morphologies of cells from each group were examined under an inverted microscope. Fig. 1A shows that 


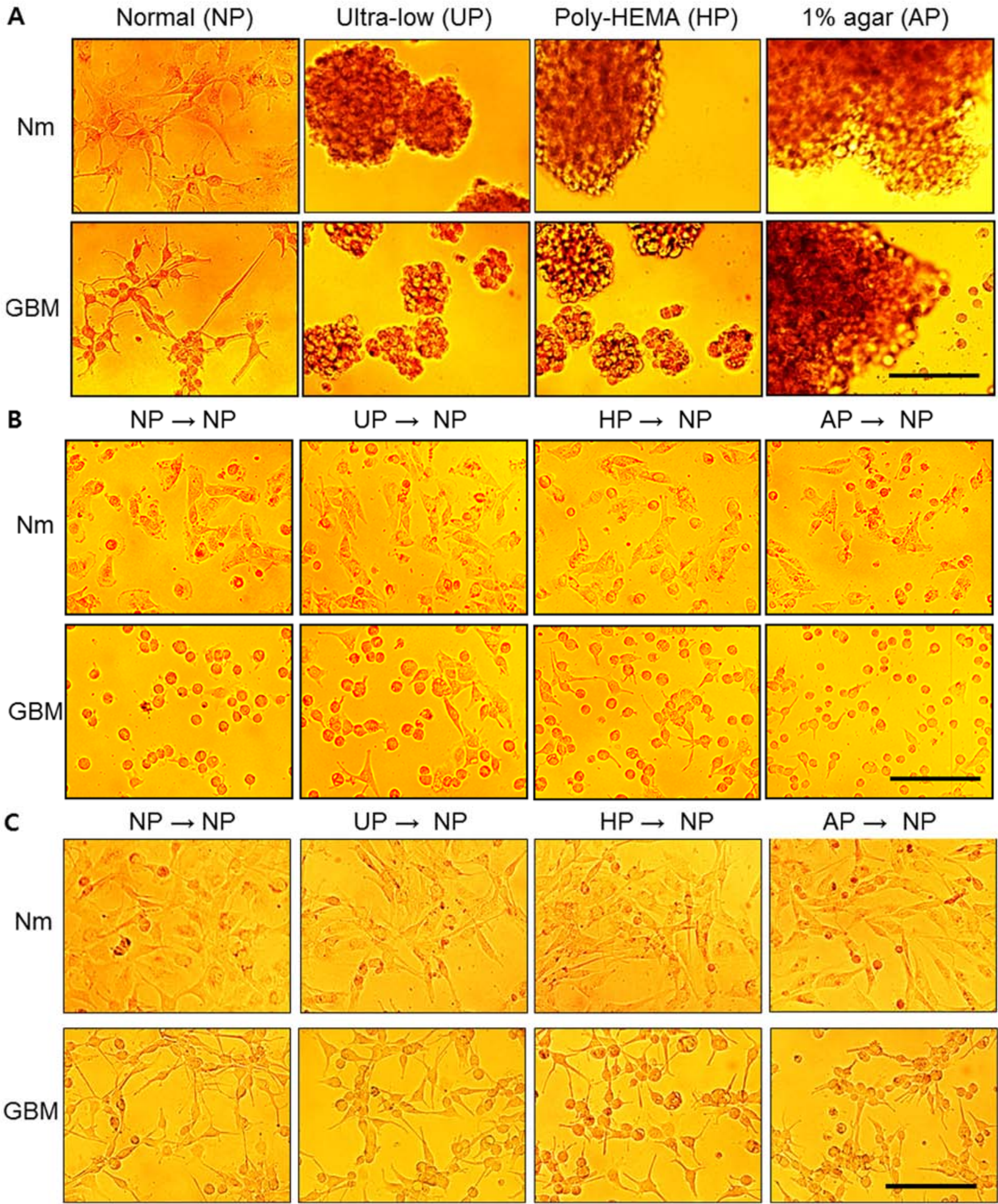

Figure 1. Cellular morphology under different cell culture conditions. (A) Cells were cultured for $72 \mathrm{~h}$ and cellular morphology was observed with an inverted phase contrast microscope. Cells were imaged after $4 \mathrm{~h}$ (B) or $24 \mathrm{~h}$ (C) of seeding on NP under different conditions. Scale bar indicates $200 \mu \mathrm{m}$.

the A172 cells in Nm on NP (designated as controls) grew as a monolayer, while those in serum-free medium supplemented with growth factors (GBM, $10 \mathrm{ng} / \mathrm{ml} \mathrm{bFGF}$ and EGF) on NP appeared loosely attached on the plates with some cells showing stellate projections. In contrast, cells cultured on the other plates (UP, HP and AP) in the Nm condition formed floating aggregates, while those cultured on UP and HP formed sphere-like colonies in GBM. To examine whether they could re-adhere to NP, cells or colonies from each group were dissociated using trypsin and seeded onto NP under the same media conditions. After $4 \mathrm{~h}$, most cells cultured in Nm on NP, UP, HP and AP showed stable adherence to NP, whereas those cultured in GBM showed delayed adherence to NP irrespective of the previous plate conditions (Fig. 1B). After $24 \mathrm{~h}$, most cells in Nm or GBM on the four surface types adhered to NP, but those cultured in GBM showed increased populations with elongated and fibroblast-like morphologies (Fig. 1C). 

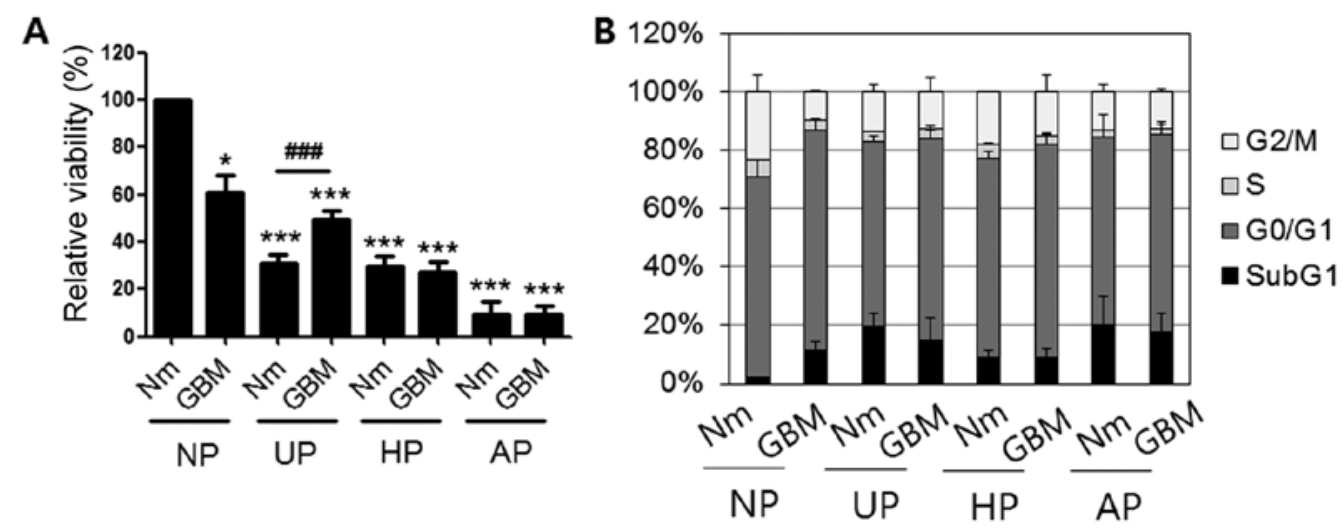

Figure 2. Cell viability, cell cycle and western blotting. Cells were analyzed as described in the Materials and methods after culturing for $72 \mathrm{~h}$. (A) Relative activity was compared to the viability of cells in Nm on NP. Data were derived from three independent experiments and reported as means \pm SE. "P $<0.05$ and ${ }^{* *} \mathrm{P}<0.01$ vs. Nm on the NP group; ${ }^{\mathrm{P}}<0.05$ vs. Nm on the same plate. (B) The cell cycle distribution was analyzed by flow cytometry. The graph is based on three independent measurements.
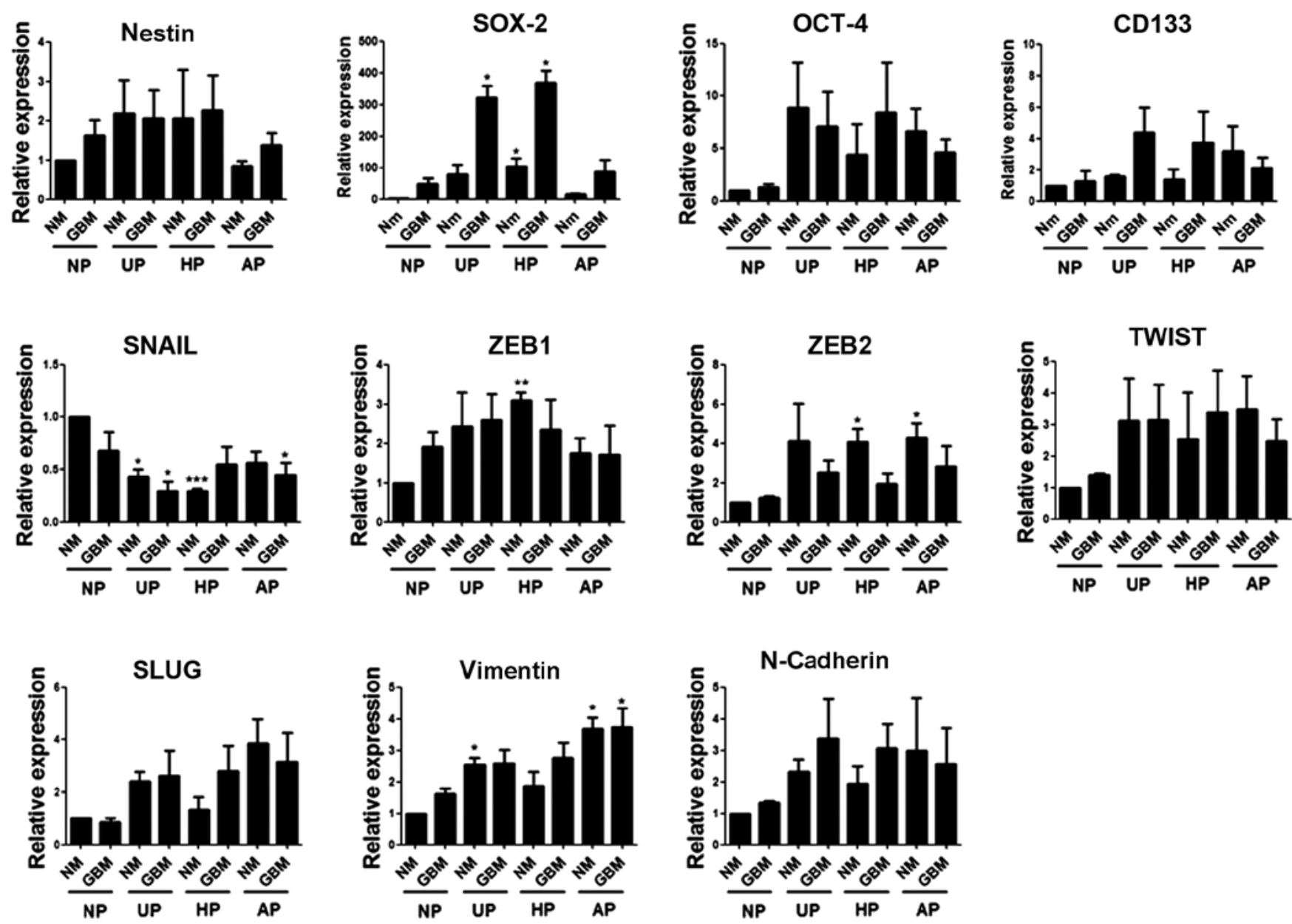

Figure 3. Expression of stemness- and EMT-related genes under different cell culture conditions. qRT-PCR analysis was carried out with the specific primers described in Table I. Data are reported as means $\pm \mathrm{SE}$ from three independent experiments. ${ }^{*} \mathrm{P}<0.05,{ }^{* * *} \mathrm{P}<0.01$ and ${ }^{* * *} \mathrm{P}<0.05$ vs. Nm on the NP group.

Cell viability decreased and subG1 proportion increased under conditions of serum-deprivation and non-adhesion. To examine cellular viability under the various conditions, equal numbers of cells from each condition were seeded on plates $\left(1 \times 10^{4} /\right.$ well $)$ and incubated with tetrazolium chloride to monitor mitochondrial reductase activity. Fig. 2A shows that the relative viability of cells in GBM on NP $(61 \pm 6.9 \%)$ was $\sim 40 \%$ lower than that of the control. Moreover, cells in Nm and GBM on three types of plates (UP, HP and AP) had significantly lower activities than those in GBM on NP. Specifically, cellular activity on AP was the lowest among the conditions examined $(9.3 \pm 5.32 \%$ in $\mathrm{Nm}$ and $9.39 \pm 3.88 \%$ in GBM). We also performed cell cycle analysis by flow cytometry after staining the cells with PI (Fig. 2B). Compared with control 

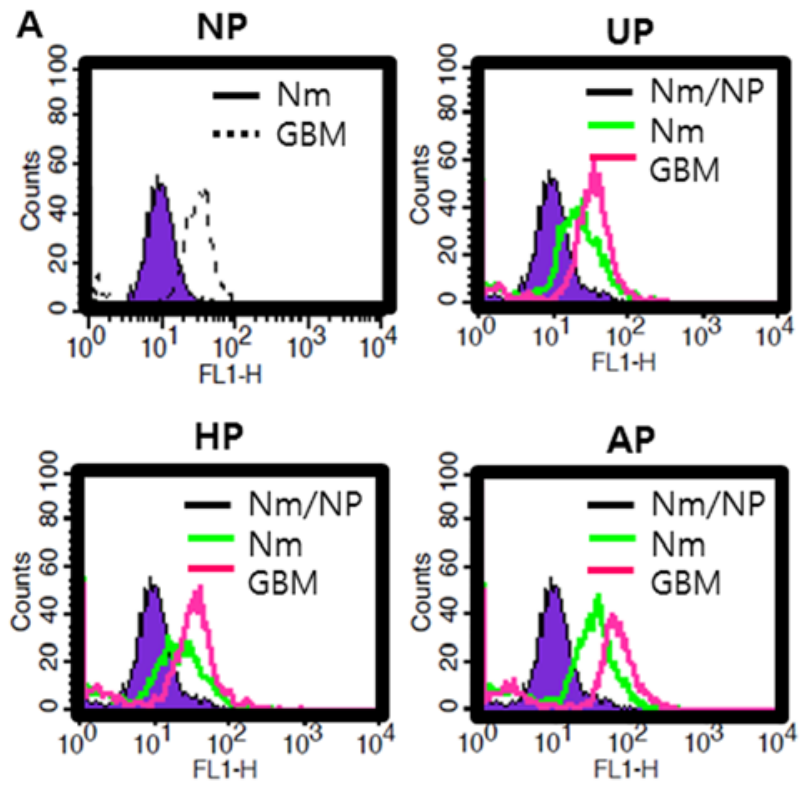

B

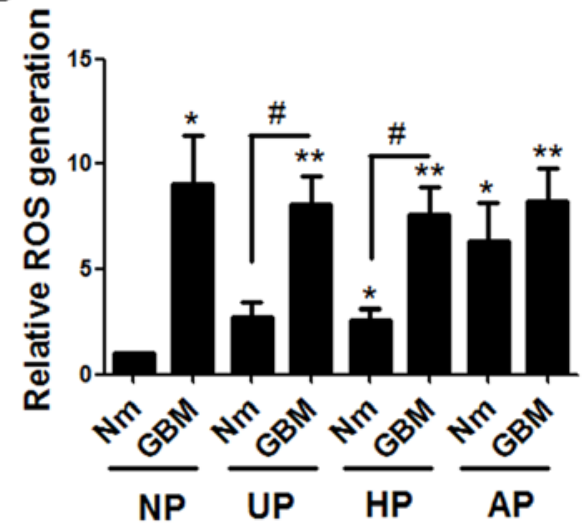

Figure 4. Measurements of ROS generation under different cell culture conditions. (A) Cells were analyzed by flow cytometry, represented as a histogram and overlaid with the histograms for the cells cultured under different conditions. (B) The percentage of positive fluorescent cells was obtained using Cell Quest software and is represented as fold change. Data are reported as means $\pm \mathrm{SE}$ from three independent experiments. ${ }^{*} \mathrm{P}<0.05,{ }^{* *} \mathrm{P}<0.01 \mathrm{vs}$. Nm on the $\mathrm{NP}$ group; ${ }^{\#} \mathrm{P}<0.05$ vs. Nm on the same plate.

cells $(2.05 \pm 0.03 \%)$, there was a $\sim 10 \%$ increase in the subG1 proportion of cells under GMB culture conditions (GBM/NP, $11.4 \pm 3.2 \%$ ) together with decreased $\mathrm{G} 2 / \mathrm{M}$ phase. However, on the other plates, incubation in GBM did not increase the subG1 proportion (Nm/UP, 19.88 $\pm 3.96 \%$; GBM/UP, 14.64 $\pm 8.12 \%$; $\mathrm{Nm} / \mathrm{HP}, 9.16 \pm 2.22 \%$; GBM/HP, 8.82 $\pm 3.33 \%$; Nm/AP, $20.13 \pm 9.83 \%$; and GBM/AP, $17.76 \pm 6.58 \%$ ).

SOX-2 mRNA levels increased markedly in GBM on UP and $H P$. To determine whether combined culture conditions affected the self-renewal and EMT abilities of these cells, the expression levels of four stem cell markers and seven EMT-related markers were examined by real-time PCR using specific primers (Table I). Compared with the control, SOX-2 mRNA levels showed the greatest increase in GBM on both UP and HP (fold-change: 321 and 369, respectively). CD133 expression also increased in GBM on UP and HP but to a lesser extent, which was not statistically significant. Among the EMT markers, SNAIL expression decreased on three plate types (UP, HP and AP). The mRNA levels of the other EMT markers appeared to be dependent on the plate type rather than the medium type (Fig. 3).

Both serum-deprivation and non-adherent conditions enhanced ROS accumulation. The effects of different culture conditions on ROS levels were investigated because ROS may be an important factor in regulation of stem cells and the chemoresistance of cancer stem cells (32-34). Performance was assessed by the conversion of non-fluorescent $\mathrm{H}_{2} \mathrm{DCF}$ to the fluorescent form (35). Fig. 4 shows that the level of ROS generation in the cells cultured on UP or HP in normal medium was about double that in those cultured on normal plates. Serum deprivation GBM on UP or HP further increased ROS generation by 8 -fold. Interestingly, ROS levels from cells cultured in both $\mathrm{Nm}$ and GBM on AP were 6 - and 8-fold higher, respectively, than the control. These data indicate that the effect of serum deprivation on ROS accumulation is greater than that of the non-adherent condition.

SOD2 expression was induced under non-adherent conditions. As ROS generation was increased by serum deprivation, which was also effective for SOX-2 induction, we examined whether alterations in SOD1 and SOD2 expression were responsible for ROS accumulation and SOX-2 induction under serum deprivation or non-adherent conditions. Western blotting indicated that the level of SOX-2 expression was higher in the GBM condition than in normal medium on all four plate types, which was similar to the mRNA profile (Fig. 5A). While SOD1 expression showed no prominent pattern with respect to serum deprivation or plate condition, the SOD2 expression profile exhibited an inverse relationship with that of SOX-2 (Fig. 5B and $\mathrm{C}$ ). However, with the exception of values from UP in $\mathrm{Nm}$ or GBM, the correlations were not statistically significant. Dot plot analysis was performed using the mean values of the SOX-2 and SOD2 protein levels. Fig. 5D shows that the two protein values from each group could be classified into a significantly larger SOX-2-expressing group (gray-dotted circle; GBM on three plate types) and a SOD2-expressing group (black ellipse; Nm on UP, HP and AP). SOX-2 expression was shown to be dependent on the GBM condition, while SOD2 expression was dependent on the non-adherent conditions. Finally, cells were treated with NAC, a general ROS scavenger, to determine whether NAC could reverse the SOX-2 induction observed under our culture conditions. Western blotting was performed using antibodies to SOX-2, SOD1, and SOD2 after treatment with $10 \mathrm{mM}$ NAC under the same conditions for 72 h. Fig. 6 shows that NAC treatment did 

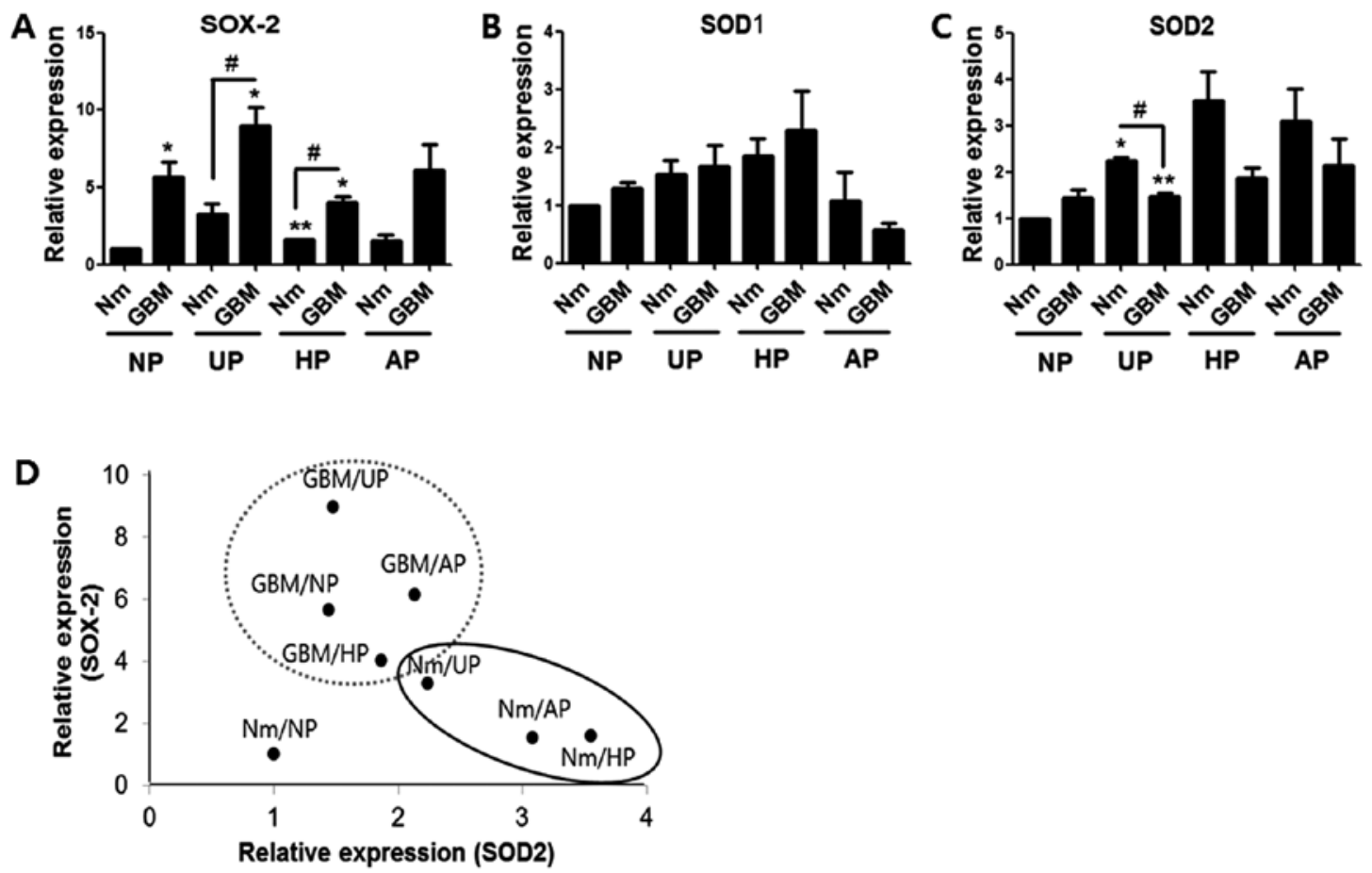

Figure 5. Protein levels of SOX-2, SOD1, and SOD2 for different cell culture conditions. (A-C) Protein levels were analyzed by western blotting using specific antibodies. Protein expression levels of the cells were analyzed using Image J software. The expression ratio relative to the control was calculated after compensating for the intensity of $\beta$-actin from each group. Data are reported as means \pm SE from three independent experiments. ${ }^{*} \mathrm{P}<0.05$ and ${ }^{* * *} \mathrm{P}<0.01 \mathrm{vs}$. Nm on the NP group; ${ }^{*} \mathrm{P}<0.05$ vs. Nm on the same plate. (D) Dot plot analysis was performed using the mean protein levels shown in A and C. The gray-dotted circle indicates the significantly increased SOX2-expressing group. The black ellipse indicates the SOD2-expressing group.

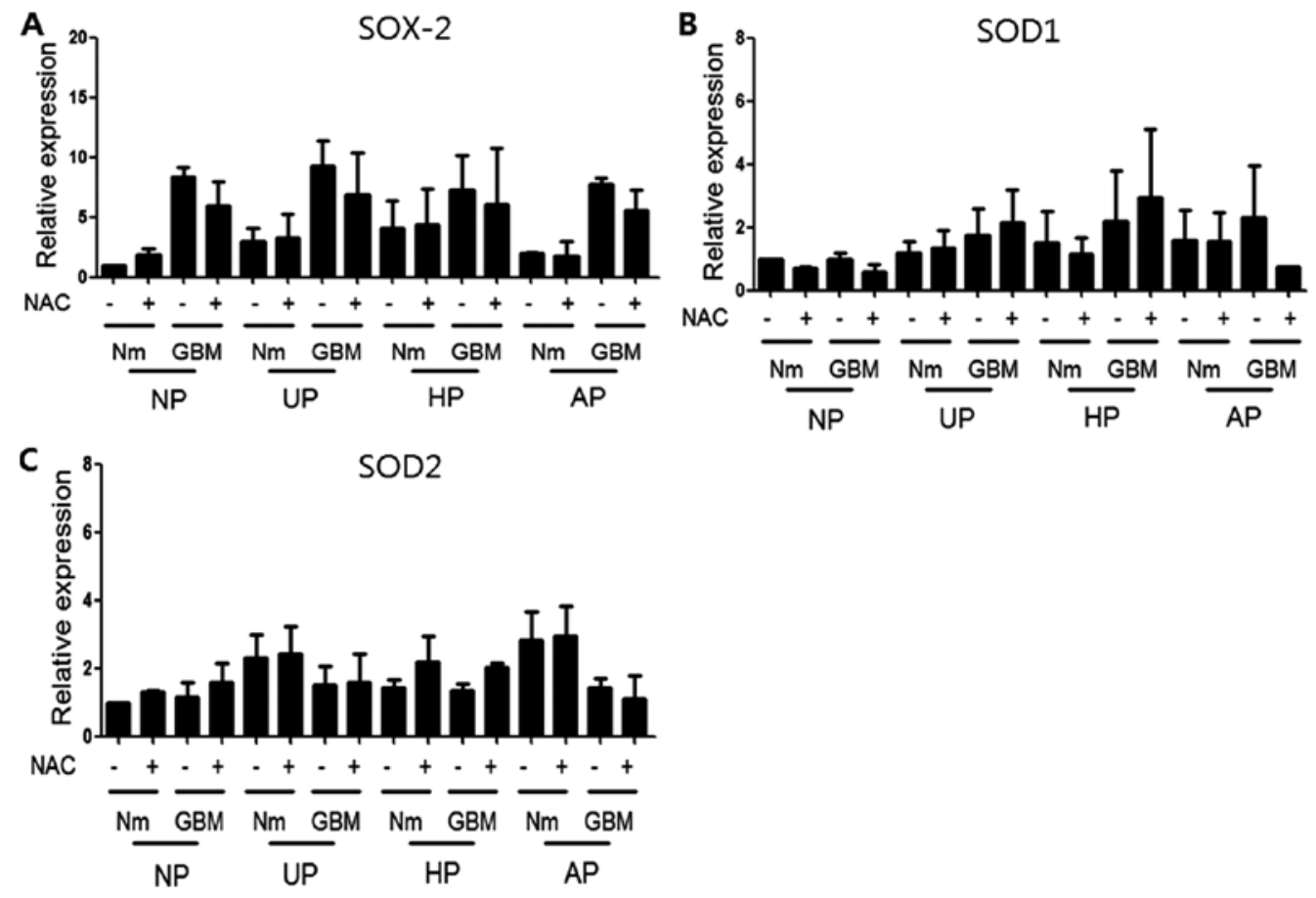

Figure 6. Treatment with NAC did not block increased protein levels of SOX-2, SOD1 or SOD2 under different culture conditions. (A-C) Cells incubated with $10 \mathrm{mM}$ NAC were maintained for $72 \mathrm{~h}$ and western blotting analysis was performed using specific antibodies. Data are reported as means \pm SE from three independent experiments.

not block the induction of SOX-2 or SOD2, suggesting that it was independent of ROS. Data from qRT-PCR analyses also revealed no significant recovery of SOX-2 with NAC treatment (data not shown).

\section{Discussion}

The isolation and enrichment of CSCs in vitro are important for targeting strategies and drug screening for anticancer 
therapy. It would be beneficial to be able to characterize cancer cells under different culture conditions in vitro to better understand the features of CSCs. This study examined the combined effects of serum deprivation and culture plate surface type on the morphology, viability, and markers for stemness and EMT in A172 glioblastoma cells. These cells were previously shown to have aggressive migration ability and ROS accumulation in response to appropriate stimuli $(36,37)$.

In the presence of serum, A172 cells grew as a monolayer while those on UP, HP and AP did not attach to the bottom and formed colonies, which led to decreased viability and increased apoptosis (Figs. 1A and 2A and B). However, most of the cells from each plate regained the adhesion ability and apparent viability when allowed to re-adhere to NP after $72 \mathrm{~h}$ of culture on each plate. These observations indicated that the interaction with the extracellular matrix (ECM) is an important prerequisite for the survival of cancer cells (Fig. 1A-C). The results also demonstrated that incubation of cells on various plates in serum-free GBM did not further affect the viability, except on NP, but delayed the re-adhesion on NP with an appearance of more elongated phenotypes after $72 \mathrm{~h}$ of culture. This delay is attributed to vitronectin and fibronectin in serum (38). It is plausible that the serum-free condition is less critical to the maintenance of viability but is more effective than the non-adherent condition for enrichment of cancer stem cell-like cells.

Our results based on the mitochondrial reductase activity and subG1 fractions were inconsistent for the evaluation of cell viability. This indicated that the reduced viability estimated by mitochondrial reductase activity did not necessarily represent apoptotic cells but rather the metabolically inactive status, which could be stimulated by environmental changes. These results also reinforce the heterogeneous and dynamic nature of cancer cells, which can show different responses under these harsh conditions. It is significant that cell incubation on AP exhibited the lowest activity in mitochondrial reductase and highest proportions of subG1 and highest ROS accumulation among the culture plate conditions, and that serum deprivation did not have considerable effects. Therefore, culture on AP rather than HP in the presence of serum seemed be the most efficient way to induce anoikis, which is an important defense mechanism for preventing the anchorage-independent survival of tumor cells (39).

SOX-2 was significantly increased by the GBM condition, and was especially prominent on UP and HP at both mRNA and protein levels (Figs. 3B and 5). These results support the importance of serum-free conditions on enrichment of CSCs. Our findings were consistent with the previous report that serum deprivation-induced bone marrow stem cells show upregulated expression of stemness-related protein, such as SOX-2 (40).

SOX-2 has been suggested to be a marker of stem cells (7) and CSCs $(41,42)$. Thus, culture of cancer cells under conditions of serum deprivation on UP or HP could be useful for the isolation and enrichment of SOX-2-expressing CSCs. The expression of some EMT-related genes, such as ZEB2, TWIST and VIMENTIN, was induced by non-adherent conditions rather than by serum deprivation. However, these genes were expressed with different statistical significances, which suggested that the acquisition of both stemness and
EMT properties could be provided to cancer cells only by very subtle and complex changes in the environment.

Fig. 4 shows that significantly higher ROS levels were observed in GBM on NP as well as on non-adherent plates (UP, HP and AP). The higher levels seemed to be more dependent on serum deprivation than on the presence of a non-adherent surface. ROS is a critical factor for maintaining stemness by the expression of SOX-2 (43), and SOD2 promotes migration and invasion and protects cells from ROS-mediated cell death (44-46). Therefore, we hypothesized that a ROS scavenger would block SOX-2 induction under our cell culture conditions. NAC treatment, however, did not prevent SOX-2 levels at the mRNA (data not shown) or protein level (Fig. 6A). These results indicated that induction of SOX-2 was not dependent on ROS under our conditions. However, the induction profiles of SOX-2 with SOD2 under different culture conditions suggested some influence of SOD2 on ROS and SOX-2 induction. This indication merits further investigation.

Although Sauerzweig et al (40) suggested that serum deprivation is an enrichment process for CSCs, growth factors are also required to maintain the self-renewal of brain tumor stem cells (23). Therefore, we could not exclude the effects of the growth factors EGF and bFGF, which were included in GBM in the present study, on the expression of SOX-2 as well as on ROS accumulation. Another limitation of our study was that the viability and expression of markers for CSC and EMT were examined after only $72 \mathrm{~h}$ of incubation; this is probably insufficient time to fully select the CSCs. Therefore, the effects of serum deprivation only and long-term culture on different plate conditions should also be examined to determine the most efficient culture conditions for CSCs.

\section{Acknowledgements}

This research was supported by the Basic Science Research Program through the National Research Foundation of Korea (NRF) funded by the Ministry of Science, ICT and Future Planning (2014R1A1A1006961 and 2012R1A5A2047939).

\section{References}

1. Jordan CT, Guzman ML and Noble M: Cancer stem cells. N Engl J Med 355: 1253-1261, 2006.

2. Kapoor A and Kumar S: Cancer stem cell: A rogue responsible for tumor development and metastasis. Indian J Cancer 51: 282-289, 2014.

3. Chinn SB, Darr OA, Peters RD and Prince ME: The role of head and neck squamous cell carcinoma cancer stem cells in tumorigenesis, metastasis, and treatment failure. Front Endocrinol (Lausanne) 3: 90, 2012.

4. Sahlberg SH, Spiegelberg D, Glimelius B, Stenerlöw B and Nestor M: Evaluation of cancer stem cell markers CD133, CD44, CD24: Association with AKT isoforms and radiation resistance in colon cancer cells. PLoS One 9: e94621, 2014.

5. He J, Shan Z, Li L, Liu F, Liu Z, Song M and Zhu H: Expression of glioma stem cell marker CD133 and $O^{6}$-methylguanine-DNA methyltransferase is associated with resistance to radiotherapy in gliomas. Oncol Rep 26: 1305-1313, 2011.

6. Tam WL and Ng HH: Sox2: Masterminding the root of cancer. Cancer Cell 26: 3-5, 2014.

7. Chen S, Choo AB, Nai-Dy W, Heng-Phon $T$ and Oh SK: Knockdown of Oct-4 or Sox-2 attenuates neurogenesis of mouse embryonic stem cells. Stem Cells Dev 16: 413-420, 2007. 
8. Chiou SH, Yu CC, Huang CY, Lin SC, Liu CJ, Tsai TH, Chou SH, Chien CS, Ku HH and Lo JF: Positive correlations of Oct-4 and Nanog in oral cancer stem-like cells and high-grade oral squamous cell carcinoma. Clin Cancer Res 14: 4085-4095, 2008.

9. Ishiwata T, Teduka K, Yamamoto T, Kawahara K, Matsuda Y and Naito Z: Neuroepithelial stem cell marker nestin regulates the migration, invasion and growth of human gliomas. Oncol Rep 26: 91-99, 2011

10. Jung MJ, Rho JK, Kim YM, Jung JE, Jin YB, Ko YG, Lee JS, Lee SJ, Lee JC and Park MJ: Upregulation of CXCR4 is functionally crucial for maintenance of stemness in drug-resistant non-small cell lung cancer cells. Oncogene 32: 209-221, 2013.

11. Smit MA, Geiger TR, Song JY, Gitelman I and Peeper DS: A Twist-Snail axis critical for TrkB-induced epithelial-mesenchymal transition-like transformation, anoikis resistance, and metastasis. Mol Cell Biol 29: 3722-3737, 2009.

12. Zheng $\mathrm{H}$ and Kang Y: Multilayer control of the EMT master regulators. Oncogene 33: 1755-1763, 2014.

13. Singh SK, Clarke ID, Terasaki M, Bonn VE, Hawkins C, Squire J and Dirks PB: Identification of a cancer stem cell in human brain tumors. Cancer Res 63: 5821-5828, 2003.

14. Clément V, Dutoit V, Marino D, Dietrich PY and Radovanovic I: Limits of CD133 as a marker of glioma self-renewing cells. Int J Cancer 125: 244-248, 2009.

15. Davies MA, Lu Y, Sano T, Fang X, Tang P, LaPushin R, Koul D, Bookstein R, Stokoe D, Yung WK, et al: Adenoviral transgene expression of MMAC/PTEN in human glioma cells inhibits Akt activation and induces anoikis. Cancer Res 58: 5285-5290, 1998.

16. Minett TW, Tighe BJ, Lydon MJ and Rees DA: Requirements for cell spreading on polyHEMA coated culture substrates. Cell Biol Int Rep 8: 151-159, 1984.

17. Fiucci G, Ravid D, Reich R and Liscovitch M: Caveolin-1 inhibits anchorage-independent growth, anoikis and invasiveness in MCF-7 human breast cancer cells. Oncogene 21: 2365-2375, 2002

18. Xie TX, Zhou G, Zhao M, Sano D, Jasser SA, Brennan RG and Myers JN: Serine substitution of proline at codon 151 of TP53 confers gain of function activity leading to anoikis resistance and tumor progression of head and neck cancer cells. Laryngoscope 123: 1416-1423, 2013

19. Gomez-Casal R, Bhattacharya C, Ganesh N, Bailey L, Basse P, Gibson M, Epperly M and Levina V: Non-small cell lung cancer cells survived ionizing radiation treatment display cancer stem cell and epithelial-mesenchymal transition phenotypes. Mol Cancer 12: 94, 2013.

20. Krishnamurthy S, Dong Z, Vodopyanov D, Imai A, Helman JI Prince ME, Wicha MS and Nör JE: Endothelial cell-initiated signaling promotes the survival and self-renewal of cancer stem cells. Cancer Res 70: 9969-9978, 2010.

21. Kesanakurti D, Chetty C, Rajasekhar Maddirela D, Gujrati M and Rao JS: Functional cooperativity by direct interaction between PAK4 and MMP-2 in the regulation of anoikis resistance, migration and invasion in glioma. Cell Death Dis 3: e445, 2012

22. Guo D, Xu BL, Zhang XH and Dong MM: Cancer stem-like side population cells in the human nasopharyngeal carcinoma cell line CNE-2 possess epithelial mesenchymal transition properties in association with metastasis. Oncol Rep 28: 241-247, 2012.

23. Pestereva E, Kanakasabai S and Bright JJ: PPAR $\gamma$ agonists regulate the expression of stemness and differentiation genes in brain tumour stem cells. Br J Cancer 106: 1702-1712, 2012

24. Frisch SM and Screaton RA: Anoikis mechanisms. Curr Opin Cell Biol 13: 555-562, 2001.

25. Grossmann J: Molecular mechanisms of 'detachment-induced apoptosis - Anoikis'. Apoptosis 7: 247-260, 2002

26. Zhong $X$ and Rescorla FJ: Cell surface adhesion molecules and adhesion-initiated signaling: Understanding of anoikis resistance mechanisms and therapeutic opportunities. Cell Signal 24: 393-401, 2012

27. Zhan M, Zhao H and Han ZC: Signalling mechanisms of anoikis Histol Histopathol 19: 973-983, 2004.

28. Shen M and Horbett TA: The effects of surface chemistry and adsorbed proteins on monocyte/macrophage adhesion to chemically modified polystyrene surfaces. J Biomed Mater Res 57: 336-345, 2001.
29. Hardee ME, Marciscano AE, Medina-Ramirez CM, Zagzag D, Narayana A, Lonning SM and Barcellos-Hoff MH: Resistance of glioblastoma-initiating cells to radiation mediated by the tumor microenvironment can be abolished by inhibiting transforming growth factor- $\beta$. Cancer Res 72: 4119-4129, 2012.

30. Silginer M, Weller M, Ziegler U and Roth P: Integrin inhibition promotes atypical anoikis in glioma cells. Cell Death Dis 5: e1012, 2014.

31. Hong X, Chedid K and Kalkanis SN: Glioblastoma cell line-derived spheres in serum-containing medium versus serum-free medium: A comparison of cancer stem cell properties. Int J Oncol 41: 1693-1700, 2012.

32. Bigarella CL, Liang R and Ghaffari S: Stem cells and the impact of ROS signaling. Development 141: 4206-4218, 2014.

33. Suzuki S, Okada M, Shibuya K, Seino M, Sato A, Takeda H, Seino S, Yoshioka T and Kitanaka C: JNK suppression of chemotherapeutic agents-induced ROS confers chemoresistance on pancreatic cancer stem cells. Oncotarget 6: 458-470, 2014

34. Ali Azouaou S, Emhemmed F, Idris-Khodja N, Lobstein A, Schini-Kerth V, Muller CD and Fuhrmann G: Selective ROS-dependent p53-associated anticancer effects of the hypoxoside derivative rooperol on human teratocarcinomal cancer stem-like cells. Invest New Drugs 33: 64-74, 2014.

35. Myhre O, Andersen JM, Aarnes H and Fonnum F: Evaluation of the probes 2',7'-dichlorofluorescin diacetate, luminol, and lucigenin as indicators of reactive species formation. Biochem Pharmacol 65: 1575-1582, 2003.

36. Lee YD, Cui MN, Yoon HH, Kim HY, Oh IH and Lee JH: Down-modulation of Bis reduces the invasive ability of glioma cells induced by TPA, through NF- $\mathrm{B}$ mediated activation of MMP-9. BMB Rep 47: 262-267, 2014.

37. Yoo HJ, Im CN, Youn DY, Yun HH and Lee JH: Bis is induced by oxidative stress via activation of HSF1. Korean J Physiol Pharmacol 18: 403-409, 2014.

38. Hayman EG, Pierschbacher MD, Suzuki S and Ruoslahti E: Vitronectin - a major cell attachment-promoting protein in fetal bovine serum. Exp Cell Res 160: 245-258, 1985.

39. Paoli P, Giannoni E and Chiarugi P: Anoikis molecular pathways and its role in cancer progression. Biochim Biophys Acta 1833: 3481-3498, 2013

40. Sauerzweig S, Munsch T, Lessmann V, Reymann KG and Braun H: A population of serum deprivation-induced bone marrow stem cells (SD-BMSC) expresses marker typical for embryonic and neural stem cells. Exp Cell Res 315: 50-66, 2009.

41. Ling GQ, Chen DB, Wang BQ and Zhang LS: Expression of the pluripotency markers Oct $3 / 4$, Nanog and Sox 2 in human breast cancer cell lines. Oncol Lett 4: 1264-1268, 2012.

42. Favaro R, Appolloni I, Pellegatta S, Sanga AB, Pagella P, Gambini E, Pisati F, Ottolenghi S, Foti M, Finocchiaro G, et al: Sox 2 is required to maintain cancer stem cells in a mouse model of high-grade oligodendroglioma. Cancer Res 74: 1833-1844, 2014.

43. Kim MC, Cui FJ and Kim Y: Hydrogen peroxide promotes epithelial to mesenchymal transition and stemness in human malignant mesothelioma cells. Asian Pac J Cancer Prev 14: 3625-3630, 2013

44. Liu Z, He Q, Ding X, Zhao T, Zhao L and Wang A: SOD2 is a $\mathrm{C}$-myc target gene that promotes the migration and invasion of tongue squamous cell carcinoma involving cancer stem-like cells. Int J Biochem Cell Biol 60: 139-146, 2015.

45. Im CN, Lee JS, Zheng Y and Seo JS: Iron chelation study in a normal human hepatocyte cell line suggests that tumor necrosis factor receptor-associated protein 1 (TRAP1) regulates production of reactive oxygen species. J Cell Biochem 100: 474-486, 2007.

46. Ruggeri P, Farina AR, Di Ianni N, Cappabianca L, Ragone M, Ianni G, Gulino A and Mackay AR: The TrkAIII oncoprotein inhibits mitochondrial free radical ROS-induced death of SH-SY5Y neuroblastoma cells by augmenting SOD2 expression and activity at the mitochondria, within the context of a tumour stem cell-like phenotype. PLoS One 9: e94568, 2014. 